\title{
ROLE OF PER OPERATIVE USE OF INTRAVENOUS MAGNESIUM IN REDUCING THE INCIDENCE OF PER AND POST OPERATIVE ARRHYTHMIAS IN CONVENTIONAL CORONARY ARTERY BYPASS GRAFT SURGERY
}

\author{
Alam $\mathrm{MMU}^{1}$,Ahsan $\mathrm{MN}^{2}$,Rahman $\mathrm{MMM}^{3}$, Khan $\mathrm{M}^{4}$, Hossain $\mathrm{MM}^{5}$, Tauhid-Ul-Mulk ${ }^{6}$, Sultana $\mathrm{MS}^{7}$
}

\begin{abstract}
Introduction: Arrhythmias are not uncommon after Coronary Artery Bypass Graft (CABG) surgery. There is increasing evidence that Magnesium, the important intracellular cation plays a crucial role in preventing and terminating cardiac arrhythmias.
\end{abstract}

Objectives: The aim of this study was to establish the role of peroperative use of intravenous Magnesium in reducing the incidence of per and postoperative arrhythmias in CABG surgery.

Materials and methods: A total sixty (Group-I 30 and Group-II 30) patients of both sexes and different ages undergoing conventional $\mathrm{CABG}$ surgery under general anesthesia in $\mathrm{CMH}$ Dhaka from January 2009 to December 2011 were selected randomly. After induction, Group-I received $2 \mathrm{gm}$ of Magnesium in $100 \mathrm{ml}$ normal saline intravenously over a period of 30 minutes and Group-II received no Magnesium. Parameters recorded per and postoperatively were- aortic cross clamp time, Cardio Pulmonary Bypass (CPB) time, total surgery time, Heart Rate (HR), Systolic Blood Pressure (SBP), Diastolic Blood Pressure (DBP) and blood sample were collected on arrival to Cardiac Intensive Care Unit (CICU) and after 6, 12, and 24 hours. Results were expressed as mean \pm SD (Standard Deviation) or in frequencies (percentage) as applicable. The results were analyzed by Student's ' $t$ ' test.

Results: Magnesium levels were significantly $(p<0.05)$ low in Group-II patients than that of Group-I. In Group-II patients, the fluctuations of HR, SBP and DBP were significantly $(p<0.05)$ more than that of Group-I. In Group-I patients incidence of arrhythmias were significantly $(p<0.05)$ less than that of Group-II.

Conclusion: Low serum Magnesium levels are a frequent finding after conventional CABG surgery. This acute loss of Magnesium has been suggested as an etiology of many per and postoperative arrhythmias. This study revealed that peroperative administration of Magnesium provided a significant reduction in arrhythmias per and postoperatively.

Key-Words: Intravenous Magnesium, Cardiac Arrhythmia, CABG.

1. Maj Md. Mahbub UI Alam, MBBS, DA, FCPS, Graded Spl in Anaesthesiology, CMH, Ghatail. 2. Brig Gen Md Nazmul Ahsan, MBBS, FCPS, Adv spl \& Chief Cardiac Anaesthesiologist, CMH, Dhaka. 3. Brig Gen Munshi Md Mojibur Rahman, MBBS, MCPS, FICS, FCPS, AFIC, Adv spl \& Chief Cardiovascular \& Thoracic Surgeon, CMH, Dhaka. 4. Col Musa Khan, MBBS, MS (CV\&T), FCVS, Cardiovascular \& Thoracic surgeon, CMH, Dhaka. 5. Lt Col Mir Mahmud Hossain, MBBS, FCPS, Classified Cardiac Anaesthesiologist, CMH, Dhaka. 6. Lt Col Md Tauhid-Ul-Mulk, MBBS, DA, FCPS Classified Cardiac Anaesthesiologist, CMH Dhaka. 7. Maj Most. Sarmin Sultana, MBBS, MCPS, Instructor in Biochemistry, AFMC, Dhaka. 


\section{Introduction}

Magnesium is an important intracellular cation. Magnesium is an important intracellular cation. There is increasing evidence that Magnesium plays a crucial role in in preventing and terminating cardiac arrhythmias1. The physiological role of Magnesium is to assist regulation of conventional cardiac rhythm ${ }^{2,3}$. Arrhythmias are not uncommon after Coronary Artery Bypass Graft Surgery $(\mathrm{CABG})^{4}$. The etiology of arrhythmias after CABG is multifactorial ${ }^{5}$. The factors are advanced age, male sex, hypertension, hypothyroidism, withdrawal of B-blockers, impaired cardiac function, chronic lung disease, chronic renal failure, diabetes, cardiopulmonary bypass and cardioplegia, myocardial ischemia and reperfusion, myocardial infarction, right coronary artery disease, local inflammatory reaction, metabolic disorder, excessive catecholamine and electrolyte imbalance particularly hypomagnesaemia which has also been identified as an independent predictor of postoperative Atrial Fibrillation (AF)5. Several studies have shown that $50 \%$ or more of patients with AF, 40\%-47\% supraventricular arrhythmia and 34\% ventricular arrhythmias suffer from hypomagnesaemia ${ }^{6,7,8}$.

There are reports suggested that Magnesium reduces the incidence of ventricular arrhythmia and supraventricular arrhythmias including AF by prolonging the atrial and atrioventricular nodal refractory period ${ }^{1,6}$. These different forms of arrhythmias have the same clinical implications in early recovery phase of patients after cardiac surgery ${ }^{9,10}$. Potential complications of postoperative arrhythmia include thromboembolic events, haemodynamic compromise and increase length of stay and cost of hospitalisation ${ }^{\mathbf{1 0 , 1 1 , 1 2}}$.

Hypomagnesaemia has been observed after cardiac surgery. Administration of Magnesium offers special potential benefit to a patient undergoing conventional $\mathrm{CABG}^{4}$. Advantages of Magnesium include easy availability, less cost, decreased incidence and duration of
AF and Ventricular Tachycardia (VT), improved cardiac index, and reduction in infarct size ${ }^{4}$. In human and animals models, reperfusion injury due to the release of cross clamp can be attenuated by Magnesium administration resulting in better systolic indices of contractility and reduction of mortality. The present study was designed to evaluate the effectiveness of peroperative use of intravenous magnesium in reducing the incidence of per and postoperative arrhythmias in patients undergoing conventional CABG surgery.

\section{Materials and Methods}

In this prospective comparative study a total sixty patients of both sexes and different ages (thirty patients in Group-I with Magnesium infusion and thirty in Group-II without Magnesium) undergoing conventional CABG surgery in CMH Dhaka from January 2009 to December 2011 were selected randomly. Patients included are conventional CABG surgery under general anaesthesia with the use of cardiopulmonary bypass, normal renal function and with normal sinus rhythm. Patient with acute or chronic renal failure, serum creatinine $>2.0 \mathrm{mg} / \mathrm{dl}$, using intra-aortic balloon pump, Left Ventricular Ejection Fraction (LVEF) $<30 \%$ and emergency operation were excluded.

Pre-anaesthetic checkup was done and the detail procedure was explained to the patient and informed written consent was obtained. Permission was taken from departmental review board before starting the study. Patients were pre medicated with midazolam $(7.5 \mathrm{mg})$ per oral an hour before shifting to the operating room. Patients were then connected to a cardiac monitor including 5 lead ECG during surgery. After placement of intravenous line, arterial line and central line, baseline haemodynamic parameters like Pulse, Blood Pressure (BP), $\mathrm{SPO}_{2}$ were recorded. 
All patients were induced with intravenous induction agents propofol, midazolam, and fentanyl and tracheal intubation was facilitated with non-depolarizing muscle relaxant Pancuronium bromide $(0.1 \mathrm{mg} / \mathrm{kg})$. General anaesthsia was maintained with $0.2-1 \%$ Isoflurane in air oxygen mixture and muscle relaxation was maintained with small incremental dose, $25-35 \%$ of initial dose of Pancuronium bromide. Analgesia was maintained with incremental dose of fentanyl.

Per operatively patient's vital parameters were monitored, including arrhythmias, Heart Rate (HR), Systolic Blood Pressure (SBP), Diastolic Blood Pressure (DBP), SPO2, ECG, and End-Tidal Carbon Dioxide (ETCO2). After induction, Group-I patients received study drug, 2 gm Magnesium in $100 \mathrm{ml}$ normal saline and administered intravenously over a period of 30 minutes.

All patients underwent CABG with blood cardioplegia for myocardial protection after cross clamping. Postoperatively patients were ventilated with Synchronized Intermittent Mandatory Ventilation (SIMV) and pressure support, till extubation. Serum Magnesium levels were monitored preoperatively, on shifting to Cardiac Intensive Care Unit (CICU), and later at 6 hours, 12 hours, and 24 hours postoperatively. ECG monitoring was continued peroperative and postoperative period for 24 hours and analyzed for SVT, AF, atrial flutter, non-sustained VT, and bradycardia.

Use of defibrillator and pacemaker were also noted. Peroperative complications were immediately detected and treated as per cause. Parameters recorded per and post operatively wereaortic cross clamp time, Cardio-Pulmonary Bypass (CPB) time, total surgery time, HR, SBP, DBP, and arrhythmias. Parameters were recorded at 5 minutes interval per-operatively and hourly for 24 hours during postoperative period.
All collected data were analyzed by using Statistical Package for Social Sciences (SPSS) for windows version 17.0. All results were expressed as mean \pm Standard Deviation (SD) or in frequencies (percentage) as applicable. The results were compared using Student's ' $t$ ' test. Results are considered statistically significant if $\mathrm{p}<0.05$.

There are several limitations in our study. We could not find the previous history of arrhythmias and the relation of preoperative antiarrhythmic drug therapy with post-operative arrhythmias.

\section{Results}

Patients' characteristics are shown in Table-I. There were no significant $(p>0.05)$ differences regarding age, weight, sex, preoperative LVEF, preoperative anti-arrhythmic medications, duration of myocardial infarction, New York Heart Association (NYHA) classification and cross clamp time among both the groups. Total operation time and CPB time were significantly $(\mathrm{p}<0.05)$ more in Group-II than that of Group-I. This extra time was required to stabilize the various forms of arrhythmias during weaning from CPB.

Preoperative baseline Magnesium levels were comparable in both groups. There were significantly $(p<0.05)$ low Magnesium levels in Group-II patients than that of Group-I at CICU arrival and after 6,12 , and 24 hours (Table-I). After release of cross clamp, eleven patients $(36.67 \%)$ of Group-II and four patients (13.33\%) of Group-I required defibrillation, whereas six patients $(20 \%)$ of Group-II and two patients (6.67\%) of Group-I required cardioversion (Table-I). 
Table-I: Patient's characteristics $(\mathrm{n}=60)$

\begin{tabular}{|c|c|c|c|}
\hline Characteristics & Group I $(n=30)$ & Group II $(n=30)$ & p value \\
\hline Age (years) & $48.3 \pm 7.98$ & $50.1 \pm 6.67$ & $>0.05$ \\
\hline Weight (Kg) & $63.6 \pm 8.27$ & $65.5 \pm 9.18$ & $>0.05$ \\
\hline Sex - Male:Female & $25: 5$ & $27: 3$ & $>0.05$ \\
\hline Preoperative LVEF\% & $54.1 \pm 6.9$ & $51.5 \pm 6.1$ & $>0.05$ \\
\hline LVEF\% (30 -35\%) & $2(6.67 \%)$ & $3(10 \%)$ & $>0.05$ \\
\hline \multicolumn{4}{|l|}{ Preoperative medication: } \\
\hline Calcium antagonists & $18(60 \%)$ & $14(46.67 \%)$ & $>0.05$ \\
\hline$\beta$ - blockers & $18(60 \%)$ & $23(76.67 \%)$ & $>0.05$ \\
\hline Other anti arrhythmic & $4(13.33 \%)$ & $5(16.67 \%)$ & $>0.05$ \\
\hline Combination drugs & $10(33.33 \%)$ & $12(40 \%)$ & $>0.05$ \\
\hline \multicolumn{4}{|l|}{ Myocardial infarction: } \\
\hline None & $18(60 \%)$ & $19(63.33 \%)$ & $>0.05$ \\
\hline$<6$ weeks & $5(16.67 \%)$ & $2(6.67 \%)$ & $>0.05$ \\
\hline$>6$ weeks & $7(23.33 \%)$ & $9(30 \%)$ & $>0.05$ \\
\hline \multicolumn{4}{|l|}{ NYHA Classification: } \\
\hline Class I & $12(40 \%)$ & $13(43.33 \%)$ & $>0.05$ \\
\hline Class II & $16(53.33 \%)$ & $15(50 \%)$ & $>0.05$ \\
\hline Class III & $2(6.67 \%)$ & $2(6.67 \%)$ & $>0.05$ \\
\hline \multicolumn{4}{|l|}{ Intra -operative factors: } \\
\hline Total operation time (in min) & $217.9 \pm 43.4$ & $249.1 \pm 56.8$ & $<0.05$ \\
\hline CPB time (in min) & $117.4 \pm 27.5$ & $129.8 \pm 26.9$ & $<0.05$ \\
\hline Cross clamp time (in min) & $85.6 \pm 25.2$ & $88.4 \pm 27 . \quad 4$ & $>0.05$ \\
\hline \multicolumn{4}{|l|}{ After release of cross clamp } \\
\hline Defibrillation & $4(13.33 \%)$ & $11(36.67)$ & $<0.05$ \\
\hline Cardioversion & $2(6.67 \%)$ & $6(20 \%)$ & $<0.05$ \\
\hline Baseline Serum Mg (mg/dl) & $2.11 \pm 0.24$ & $2.02 \pm 0.18$ & $>0.05$ \\
\hline Serum $\mathrm{Mg}(\mathrm{mg} / \mathrm{dl})$ in CICU at arrival & $2.02 \pm 0.31$ & $1.56 \pm 0.21$ & $<0.05$ \\
\hline Serum $\mathrm{Mg}(\mathrm{mg} / \mathrm{dl})$ in CICU at 6 hours & $2.01 \pm 0.22$ & $1.92 \pm 0.28$ & $<0.05$ \\
\hline Serum $\mathrm{Mg}(\mathrm{mg} / \mathrm{dl})$ in CI $\quad \mathrm{CU}$ at 12 hours & $2.13 \pm 0.25$ & $2.09 \pm 0.22$ & $<0.05$ \\
\hline Serum $\mathrm{Mg}(\mathrm{mg} / \mathrm{dl})$ in CICU at 24 hours & $2.19 \pm 0.21$ & $2.01 \pm 0.20$ & $<0.05$ \\
\hline
\end{tabular}

Values are mean $\pm \mathrm{SD}$ and number (percentage) as appropriate. Analysis was done by Student's ' $\mathrm{t}$ ' test.

NS: Not significance $p>0.05$ (among two groups). Sig: Significant $\mathrm{p}<0.05$ (among two groups).

Cardio-pulmonary bypass (CPB), CICU, Cardiac Intensive Care Unit (CICU).

Values of Heart Rate (HR), Systolic Blood Pressure (SBP), Diastolic Blood Pressure (DBP) mesured at different timing (before induction, before starting CPB, after starting CPB and after arrival in CICU) are shown in table-II, III and IV respectively.

Table-II: Measurement of heart rate in two groups $(\mathrm{n}=60)$

\begin{tabular}{lccc}
\hline \multicolumn{1}{c}{ Time } & Group I $(\mathbf{n = 3 0 )}$ & Group II $(\mathbf{n}=\mathbf{3 0})$ & p value \\
\hline Before induction & $72.9 \pm 10.1$ & $74.4 \pm 9.7$ & $>0.05$ \\
Before starting CPB & $69.3 \pm 8.2$ & $72.3 \pm 12.9$ & $<0.05$ \\
After finishing CPB & $66.1 \pm 7.1$ & $73.9 \pm 11.2$ & $<0.05$ \\
After arrival in CICU & $80.1 \pm 10.6$ & $88.6 \pm 15.5$ & $<0.05$ \\
\hline
\end{tabular}

Values are presented as mean \pm SD. Analysis was done by Student's ' $t$ ' test.

NS: Not significance $p>0.05$ (among two groups). Sig: Significant $p<0.05$ (among two groups).

$\mathrm{CPB}$, cardio pulmonary bypass; CICU, cardiac intensive care unit. 
Table-III: Systolic blood pressure in two groups $(\mathrm{n}=60)$

\begin{tabular}{lccc}
\hline \multicolumn{1}{c}{ Time } & Group I $(\mathrm{n}=30)$ & Group II $(\mathrm{n}=30)$ & $\mathrm{p}$ value \\
\hline Before induction & $111.5 \pm 7.5$ & $109.5 \pm 9.15$ & $>0.05$ \\
Before starting CPB & $94.5 \pm 8.9$ & $95.3 \pm 15.3$ & $<0.05$ \\
After finishing CPB & $91.2 \pm 7.4$ & $99.3 \pm 12.1$ & $<0.05$ \\
After arrival in CICU & $102.7 \pm 8.6$ & $115.5 \pm 13.8$ & $<0.05$
\end{tabular}

Values are presented as mean $\pm \mathrm{SD}$. Analysis was done by Student's ' $t$ ' test.

NS: Not sig nificance $\mathrm{p}>0.05$ (among two groups). Sig: Significant $\mathrm{p}<0.05$ (among two groups).

Cardio-Pulmonary Bypass (CPB), Cardiac Intensive Care Unit (CICU).

Table-IV: Diastolic BP in two groups $(\mathrm{n}=60)$

\begin{tabular}{lccc}
\multicolumn{1}{c}{ Time } & Group I (n=30) & Group II (n=30) & p value \\
Before induction & $77.2 \pm 7.6$ & $79.6 \pm 9.1$ & $>0.05$ \\
Before starting CPB & $64.3 \pm 7.6$ & $69.5 \pm 11.4$ & $<0.05$ \\
After finishing CPB & $61.5 \pm 8.3$ & $68.9 \pm 12.0$ & $<0.05$ \\
After arrival in CICU & $72.7 \pm 7.6$ & $75.5 \pm 11.9$ & $<0.05$
\end{tabular}

Values are presented as mean $\pm \mathrm{SD}$. Analysis was done by Student's 't' test.

NS: Not signif icance $\mathrm{p}>0.05$ (among two groups). Sig: Significant $\mathrm{p}<0.05$ (among two groups).

Cardio-Pulmonary Bypass (CPB), Cardiac Intensive Care Unit (CICU).

In group II patients, the fluctuations of HR, SBP and DBP were significantly more than that of group I patients. But before induction HR, SBP and DBP were comparable in two groups (Figures 1, 2 \& 3).

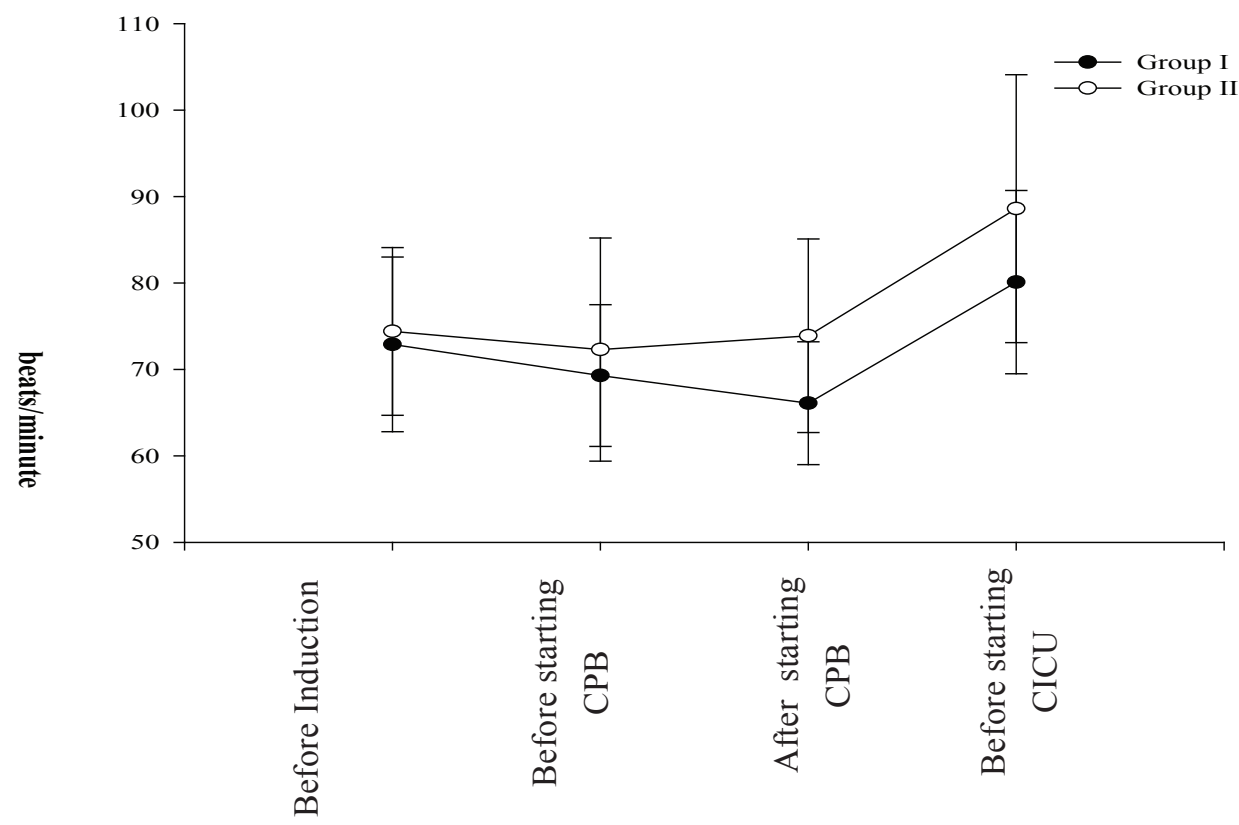

Fig-1: Graphical relation of heart rate at different time intervals between group I \& II 


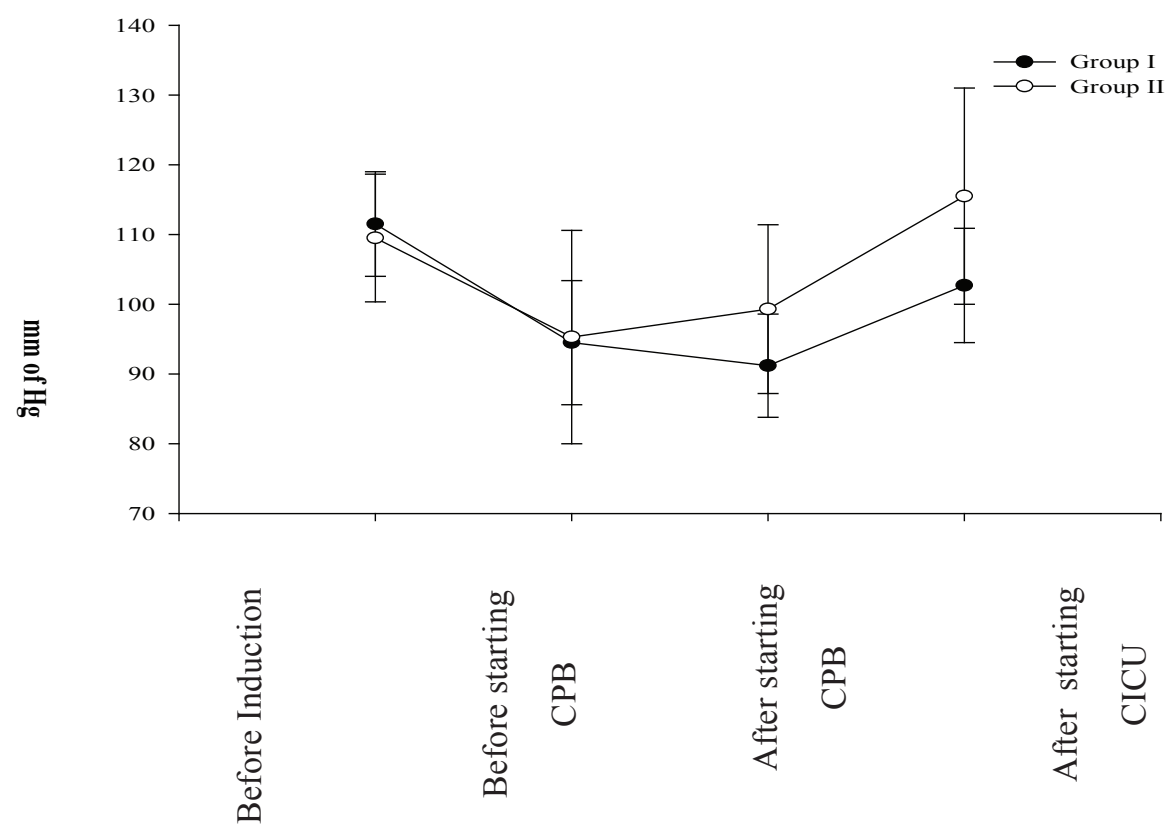

Fig-2: Graphical relation of systolic blood pressure (SBP) at different time intervals between group I and group II.

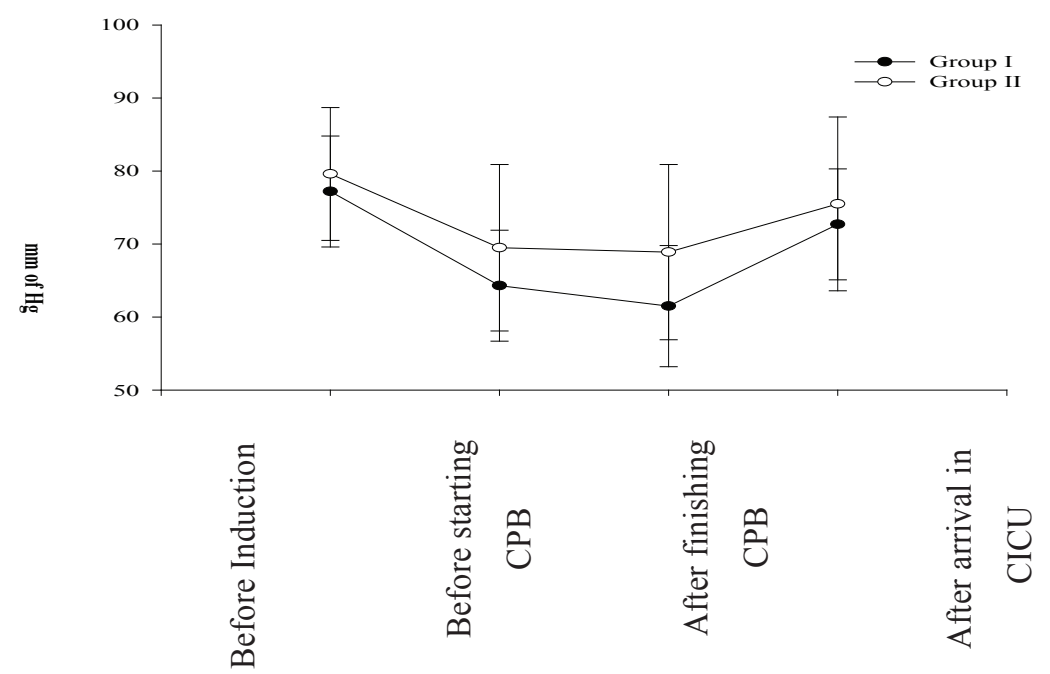

Fig-3: Graphical relation of diastolic blood pressure (DBP) at different time intervals between group I and group II. 
The incidence of intra-operative arrhythmias in operation theatre (OT) (Table V) and post-operative arrhythmias (within 24 hours) in cardiac intensive care unit (Table VI) were variable in both the groups. In group I, these incidences of arrhythmias were significantly less than that of group II. But intraoperative ventricular tachycardia and postoperative bradycardia were comparable in both groups. Nine patients (30\%) after cross clamp release and 15 patients (50\%) after finishing CPB among group I, whereas 1 patient (3.33\%) after cross clamp release and 5 patients (16.67\%) after finishing CPB among group II had no arrhythmias during intraoperative period at operation theatre (Table V). A good number of patients in group II developed multiple arrhythmias both in OT and CICU. These multiple arrhythmias were significantly less $(\mathrm{p}$ value $<0.05$ ) in group I patients both in OT and CICU (Table-V and Table-VI). Twenty patients $(66.67 \%)$ in group I developed no arrhythmia in postoperative period, in comparison to 11 patients $(36.67 \%)$ in group II (Table-VI).

Table-V: Intra operative arrhythmias at Operation Theater in two groups $(n=60)$

\begin{tabular}{lccc}
\hline Arrhythmias & Group I $(\mathbf{n}=\mathbf{3 0})$ & Group II $\mathbf{( n = 3 0 )}$ & p value \\
\hline After cross clamp release & & & \\
\hline SVT & $1(3.33 \%)$ & $5(16.67 \%)$ & $<0.05$ \\
AF & $1(3.33 \%)$ & $3(10 \%)$ & $<0.05$ \\
VT & $3(10 \%)$ & $3(10 \%)$ & $>0.05$ \\
Bradycardia & $9(30 \%)$ & $4(13.33 \%)$ & $<0.05$ \\
VPC & $5(16.67 \%)$ & $7(23.33 \%)$ & $<0.05$ \\
Multiple arrhythmias & $2(6.67 \%)$ & $7(23.33 \%)$ & $<0.05$ \\
None & $9(30 \%)$ & $1(3.33 \%)$ & $<0.05$ \\
After finishing CPB in OT & & & \\
SV T & $1(3.33 \%)$ & $2(6.67 \%)$ & $<0.05$ \\
AF & $2(6.67 \%)$ & $6(20 \%)$ & $<0.05$ \\
VT & $2(6.67 \%)$ & $5(16.67 \%)$ & $<0.05$ \\
Bradycardia & $3(10 \%)$ & $2(6.67 \%)$ & $<0.05$ \\
VPC & $3(10 \%)$ & $2(6.67 \%)$ & $<0.05$ \\
Multiple arrhythmias & $4(13.33 \%)$ & $8(26.67 \%)$ & $<0.05$ \\
None & $15(50 \%)$ & $5(16.67 \%)$ & $<0.05$
\end{tabular}

Values are presented as number (percentage). Analysis was done by Student's ' $t$ ' test.

NS: Not Significance $p>0.05$ (among two groups). Sig: Significant $p<0.05$ (among two groups). Supra Ventricular Tachycardia (SVT), Atrial Fibrillation (AF), Ventricular Tachycardia (VT), Ventricular Premature Contraction (VPC), Cardio Pulmonary Bypass (CPB). 
Table-VI: Post-operative arrhythmias (after 24 hours) at CICU in two groups ( $\mathrm{n}=60)$

\begin{tabular}{lccc}
\hline Arrhythmias & Group I $(\mathbf{n}=\mathbf{3 0})$ & Group II $(\mathbf{n}=\mathbf{3 0})$ & p value \\
\hline SVT & & & \\
AF & $2(6.67 \%)$ & $3(10 \%)$ & $<0.05$ \\
VT & $2(6.67 \%)$ & $3(10 \%)$ & $<0.05$ \\
Bradycardia & - & $2(6.67 \%)$ & $<0.05$ \\
VPC & $1(3.33 \%)$ & $1(3.33 \%)$ & $>0.05$ \\
Multiple arrhythmias & $2(6.67 \%)$ & $4(13.33 \%)$ & $<0.05$ \\
None & $3(10 \%)$ & $6(20 \%)$ & $<0.05$ \\
\hline
\end{tabular}

Values are presented as number (percentage). Analysis was done by Student's ' $t$ ' test.

N S: Not significance $p>0.05$ (among two groups). Sig: Significant $\mathrm{p}<0.05$ (among two groups).

Supra Ventricular Tachycardia (SVT), Atrial Fibrillation (AF), Ventricular Tachycardia (VT),

Ventricular Premature Contraction (VPC).

\section{Discussion}

Magnesium plays an important role in cardiovascular physiology ${ }^{13}$. The physiological role of Magnesium is to assist regulation of conventional cardiac rhythm². Hypomagnesaemia is commonly observed after cardiac surgery which may be related to haemodilution, intra-operative and postoperative cellular depletion, intra-operative diuretics use, secondary hyperaldosteronism, high level of epinephrine, increased anabolic activity, extreme stress and increased urinary $\operatorname{loss}^{14}$. In this study, mean Magnesium was reduced at CICU in Group-II and those patients were more vulnerable to develop various types of per and postoperative arrhythmias but it took 24 hours' time to normalize the Magnesium value. Although, a number of studies reveal that this normalization of Magnesium level takes more than 48 hours after arrival to CICU $12,13,15$.

Regarding haemodynamic status, in this study Magnesium treated group have shown better stability than that of non-magnesium group both peroperatively in OT and postoperatively in CICU. Heart rate, SBP and DBP fluctuations were more in non-magnesium group and these phenomenon's were predicted by a large number of authors ${ }^{12,16}$.
The incidence of AF after CABG surgery remains relatively high. Lower serum Magnesium levels have been found to be associated with an increased incidence of $\mathrm{AF}^{16,17,18}$. In this study, after releasing of cross clamp and after finishing of CPB, incidence of AF was higher in low Magnesium group. Nevertheless, it had also been found that not only AF, incidence of other supraventricular and ventricular arrhythmias were also higher in low magnesium group. These different forms of arrhythmias might have been resulted from episodes of myocardial ischaemia probably due to possible kinking of grafts or poor myocardial protection or rapid re-warming after cross clamp remova ${ }^{14,19,20}$. Low Magnesium is associated with the development of postoperative ventricular arrhythmia. For this reason, perioperative Magnesium supplementation has been suggested to play a role in the prophylaxis of arrhythmia after CABG surgery ${ }^{12,21,22}$. When Magnesium levels are corrected by the administration of Magnesium peroperatively, medical complications are significantly reduced. In our study, we used single dose of Magnesium infusion just after induction, as a result developed significantly $(\mathrm{p}<0.05)$ lower number of different types of arrhythmias in OT as well as CICU within first 24 hours period. The incidence of different arrhythmias can also be minimized by continuing the Magnesium infusion in CICU as described by many authors ${ }^{13,15,21,23}$. 
In this study, patients who developed arrhythmias were treated with antiarrhythmics medications as appropriate. We did not find any correlation between antiarrhythmics medications and Magnesium infusion. Cagli et $\mathrm{al}^{24}$ evaluated that postoperative administration of intravenous low dose Amiodarone and Magnesium sulfate combination would reduce the incidence of $\mathrm{AF}$ following $\mathrm{CABG}$ surgery.

\section{Conclusion}

Low Magnesium levels are a frequent finding after conventional CABG surgery. This acute loss of Magnesium has been regarded as an etiology of many per and post operative arrhythmias. Magnesium decreases after load, provides coronary vasodilatation, decreases platelet aggregation and protect cell against ischaemia and reperfusion. This study revealed that peroperative administration of Magnesium provided a significant reduction in arrhythmias per and postoperatively. Though, we have studied with single dose of Magnesium infusion just after induction of anaesthesia, but still there is scope to investigate different doses of Magnesium infusion at various timing in large population with variable demographic features for better outcome to minimize the incidence of multiple arrhythmias during off or on pump CABG surgery.

\section{References}

1. Shah SA, Clyne CA, Henyan N, Migeed M, Yarlagadda R, Silver BB et al. Impact of magnesium sulfate on serum magnesium concentrations and intracellular electrolyte concentrations among patients undergoing radio frequency catheter ablation. Connecticut Medicine 2008; 72(5): 261-5.

2. Ali N. The power of Magnesium: Investigation of a very important Nutrient. Available at: www.suite101.com/content/the-power-of-magnesi um-a 87676
3. Hans RL. Summaries of the latest research concerning magnesium: Magnesium helps control atrial fibrillation. PACE, 2006, 29 (Suppl 1), Abstract \#36, p.S19 (European Cardiac Arrhythmia Society, 2nd Annual Congress).

4. Hamid M, Kamal RS, Sami SA, Atiq F, Shafquat A, Naqvi HI et al. Effect of single dose magnesium on arrhythmias in patients undergoing coronary artery bypass surgery. J Pak Med Assoc 2008; 58(1): 22-7.

5. Hussain AA, Fahmy T, El-aziz AA, Othman AA, Salah M, El-fiky M. Preventive role of perioperative magnesium sulphate infusion to reduce atrial fibrillation after coronary artery bypass grafting surgery. Egypt Heart J 2008; 60(1): 3-10.

6. Onalan O, Crystal E, Daoulah A, Lau C, Crystal A, Lashevsky I. Meta-analysis of magnesium therapy for the acute management of rapid atrial fibrillation. American Journal of Cardiology 2007; 99(12): 1726-32.

7. England MR, Gordon G, Salem M, Chernow B. Magnesium administration and dysrhythmias after cardiac surgery. A placebo-controlled, double-blind, randomized trial. JAMA 1992; 268: 2395-402.

8. Toraman F, Karabulute H, Alhan HC, Dagdelen S, Tarcan S. Magnesium infusion dramatically decreases the incidence of atrial fibrillation after coronary artery bypass grafting. Ann Thorac Surg 2001; 72: 1256-62.

9. Davey MJ, Teubner D. A randomized controlled trial of magnesium sulfate in addition to usual care, for rate control in atrial fibrillation. Annals of Emergency Medicine 2005; 45(4): 347-53.

10. Brackbill ML, Moberg L. Magnesium sulfate for prevention of post operative atrial fibrillation in patient undergoing coronary artery bypasses grafting. Am J Health Syst Pharm 2005; 62(4): 397-9. 
11. Boyd WC, Thomas SJ. Pro: Magnesium should be administered to all coronary artery bypass graft surgery patients undergoing cardiopulmonary bypass. J Cardiothorac Vasc Anesth 2000; 14: 339-43.

12. Kaplan M, Kut MS, Icer UA, Demirtas MM. Intravenous magnesium sulfate prophylaxis for atrial fibrillation after coronary artery bypass surgery. J Thorac Cardiovasc Surg 2003; 125: 344-52.

13. Hazelrigg S, Boley T, Cetindag I, Moulton K, Trammel G, Polancic J et al. The efficacy of supplemental magnesium in reducing atrial fibrillation after coronary artery bypass grafting. Ann Thorac surg 2004; 77: 824-30.

14. Sahin V, Kaplan M, Bilsel S, Filizcan U, Cetemen S, Bayserke O, Bilgiç Alkaya D, Eren E. The relation between blood and tissue magnesium levels and development of atrial fibrillation after coronary artery bypass surgery. Anadolu Kardiyol Derg. 2010; 10(5): 446-51.

15. Kohno H, Koyanagi T, Kasegawa H, Miyazaki M. Three-day magnesium administration prevents atrial fibrillation after coronary artery bypass grafting. Ann Thorac Surg 2005; 79(1): 117-26.

16. Sircus M. Safer surgery with magnesium before, during and after magnesium in patients of open- heart surgery. Thorax 1972; 27(2): 212-8.

17. Caspi J, Rudis E, Bar I, Safadi T, Saute M. Effects of magnesium on myocardial after coronary artery bypass grafting. Ann Thorac Surg 1995; 59: 942-7.
18. Minato N, Katayama Y, Sakaguchi M, Itoh M. Perioperative coronary artery spasm in off-pump coronary artery bypass grafting and its possible relation with perioperative hypomagnesemia.Ann Thorac Cardiovasc Surg 2006; 12(1): 32-6.

19. Nurözler F, Tokgözoglu L, Pasaoglu I, Böke E, Ersoy U, Bozer AY. Atrial fibrillation after coronary artery bypass surgery: predictors and the role of $\mathrm{MgSO} 4$ replacement. J Card Surg 1996; 11(6): 421-7.

20. Shiga $T$, Wajima $Z$, Inouc $T$, Ogawa R. Magnesium prophylaxis for arrhythmias after cardiac surgery: a meta-analysis of randomized controlled trials. Am J Med 2004; 117(5): 325-33.

22. Parikka H, Toivonen L, Pellinen T, Verkkala K, Jarvinen A, Nieminen MS. Ventricular arrhythmia suppression by magnesium treatment after coronary artery bypass surgery. Int J Angiology 1999; 8: 165-70.

23. Dagdelen S, Yuce M, Toraman F, Karabulut H, Alhan $\mathrm{C}$. The value of $\mathrm{P}$ dispersion on predicting atrial fibrillation after coronary artery bypass surgery; effect of magnesium on $\mathrm{P}$ dispersion. Card Electrophysiol Rev 2003; 7(2): 162-4.

24. Cagli K, Ozeke O, Ergun K, Budak B, Demirtas E, Birincioglu CL et al. Effect of low-dose amiodarone and magnesium combination on atrial fibrillation after coronary artery surgery. J Card Surg 2006; 21(5):458-64. 